\title{
Identification and fine mapping of a new gene, $B P H 31$ conferring resistance to brown planthopper biotype 4 of India to improve rice, Oryza sativa L
}

\author{
G. D. Prahalada ${ }^{1}$, N. Shivakumar², H. C. Lohithaswa ${ }^{3}$, D. K. Sidde Gowda ${ }^{3}$, G. Ramkumar', Sung-Ryul Kim', \\ C. Ramachandra², Shailaja Hittalmani ${ }^{4}$, Trilochan Mohapatra ${ }^{5}$ and Kshirod K. Jena ${ }^{1 *}$ (D)
}

\begin{abstract}
Background: Rice (Oryza sativa L.) is the staple food for more than 3.5 billion people, mainly in Asia. Brown planthopper $(\mathrm{BPH})$ is one of the most destructive insect pests of rice that limits rice production. Host-plant resistance is one of the most efficient ways to overcome BPH damage to the rice crop.

Results: BPH bioassay studies from 2009 to 2015 conducted in India and at the International Rice Research Institute (IRRI), Philippines, revealed that the cultivar CR2711-76 developed at the National Rice Research Institute (NRRI), Cuttack, India, showed stable and broad-spectrum resistance to several BPH populations of the Philippines and BPH biotype 4 of India. Genetic analysis and fine mapping confirmed the presence of a single dominant gene, BPH31, in CR2711-76 conferring $\mathrm{BPH}$ resistance. The $\mathrm{BPH} 31$ gene was located on the long arm of chromosome 3 within an interval of $475 \mathrm{~kb}$ between the markers PA26 and RM2334. Bioassay analysis of the BPH31 gene in CR2711-76 was carried out against BPH populations of the Philippines. The results from bioassay revealed that CR2711-76 possesses three different mechanisms of resistance: antibiosis, antixenosis, and tolerance. The effectiveness of flanking markers was tested in a segregating population and the InDel type markers PA26 and RM2334 showed high co-segregation with the resistance phenotype. Foreground and background analysis by tightly linked markers as well as using the Infinium 6 K SNP chip respectively were applied for transferring the BPH31 gene into an indica variety, Jaya. The improved BPH31-derived Jaya lines showed strong resistance to $\mathrm{BPH}$ biotypes of India and the Philippines.

Conclusion: The new BPH31 gene can be used in BPH resistance breeding programs on the Indian subcontinent. The tightly linked DNA markers identified in the study have proved their effectiveness and can be utilized in BPH resistance breeding in rice.
\end{abstract}

Keywords: Host-plant resistance, BPH31, InDel marker, Marker-assisted selection, Resistance mechanism

\section{Background}

Rice is one of the most important and staple food crop that feed more than half of the world's population. However, rice production is severely affected by biotic and abiotic stresses. About $52 \%$ of the total global rice production is lost annually because of the damage caused by biotic factors, of which nearly $21 \%$ is attributed to the

\footnotetext{
* Correspondence: k.jena@irri.org

${ }^{1}$ Plant Breeding Division, International Rice Research Institute, DAPO Box 7777, Metro Manila, Philippines

Full list of author information is available at the end of the article
}

attack of insect pests (Khush 1979; Sogawa et al. 2003). Among the insect pests, the brown planthopper (BPH) Nilaparvata lugens (Stal) is one of the most destructive monophagous insect pests of rice throughout Asian ricegrowing countries. In recent years, BPH infestations have intensified across Asia, causing significant yield losses (Normile 2008). BPH not only causes direct damage to the rice crop by sucking plant sap, often resulting in "hopper burn," but it can also cause indirect damage by transmitting virus diseases such as rice grassy stunt and ragged stunt (Cabauatan et al. 2009). Application of 
pesticides is the most common practice to control $\mathrm{BPH}$. However, this method is costly and hazardous to the environment and health. Moreover, application of pesticide often leads to a resurgence of the pest population and affects natural BPH predators (Tanaka et al. 2000). The use of host-plant resistance is considered as one of the most economical and effective measures for BPH management (Ramkumar et al. 2016).

Considerable effort has been made in the search for rice genes conferring host-plant resistance to $\mathrm{BPH}$. Thirty BPH resistance genes have been identified (Deen et al. 2017) and mapped to six of the 12 chromosomes (2, 3, 4, 6, 11, and 12) of rice (Cheng et al. 2013). Among those, only 17 genes (BPH1, BPH2, BPH6, BPH9, BPH12, BPH14, BPH15, ВPH17, ВPH18, ВPH19, ВPH25, BPH26, BPH27, BPH28, BPH29, ВPH30 and BPH32) have been fine-mapped (Cha et al. 2008; Sun et al. 2006; Zhao et al. 2016; Qiu et al. 2012; Du et al. 2009; Lv et al. 2014; Liu et al. 2015; Jena et al. 2006; Chen et al. 2006; Myint et al. 2012; Tamura et al. 2014; Huang et al. 2013; Wu et al. 2014; Wang et al. 2015; Ren et al. 2016). However, only seven genes (BPH14, BPH17, BPH18, BPH26, $B P H 29, B P H 9$ and $B P H 32$ ) have been cloned and characterized ( $\mathrm{Du}$ et al. 2009; Liu et al. 2015; Tamura et al. 2014; Wang et al. 2015; Ji et al. 2016; Zhao et al. 2016; Ren et al. 2016). Unfortunately, most of the identified resistance genes are biotype/population specific and do not provide strong resistance to different BPH biotypes/ populations. Hence, it is imperative to identify new broad-spectrum BPH resistance genes and transfer them into elite $\mathrm{BPH}$-susceptible cultivars for stable rice production.

Plants can employ various resistance mechanisms to reduce insect damage in nature. Plant resistance to insects is generally differentiated in (1) antibiosis: a quality that reduces insect survival, growth rate, or reproduction following the ingestion of host tissue; (2) antixenosis: a quality that repels or disturbs insects, causing a reduction in colonization or oviposition; and (3) tolerance: a capacity to produce a crop of high quality and yield despite insect infestation (Alam and Cohen 1998). BPH resistance genes confer their resistance through one or a combination of the abovementioned defense mechanisms. Understanding the mode of gene action leads to better BPH management practices. However, the information on resistance mechanism of most of the identified BPH resistance genes is limited. Therefore, it is necessary to analyze the mechanisms of resistance in resistant cultivars carrying $\mathrm{BPH}$ resistance genes, which should favor the $\mathrm{BPH}$ resistance breeding programs in rice.

$\mathrm{BPH}$ populations have been categorized into four different biotypes (Khush et al. 1985; Brar et al. 2010). The population in East and Southeast Asia is reported as biotype 1, whereas biotype 2 originated in Indonesia and Vietnam as a dominant biotype (Pathak and Khush, 1979). Biotype 3 was produced in the laboratory at the International Rice Research Institute (IRRI) (Pathak and Khush 1979), whereas biotype 4 is found only in South Asia, especially on the Indian subcontinent. Although there are at least 30 reported $\mathrm{BPH}$ resistance genes, only a few genes showed their resistance potential and broad spectrum resistace to Indian biotype 4 (Deen et al. 2010; Horgan et al. 2015). In addition, most of the resistance genes were identified from rice cultivars that had inferior grain quality and agronomic traits. On the other hand, most of the rice varieties that have superior yield and agronomic traits are generally susceptible to BPH infestation. Hence, to obtain the real and maximum benefits of host-plant resistance genes, the identified resistance genes have to be introgressed into elite rice varieties without affecting their yield-associated traits and superior grain quality traits.

In order to address the constraints mentioned above, the present study was carried out with the follwoing objectives: (1) identification and genetic analysis of $\mathrm{BPH}$ resistance patterns in the resistant cultivar CR2711-76; (2) fine mapping of a major BPH resistance gene, $B P H 31$; (3) incorporation of the $B P H 31$ gene into an elite O. sativa subspecies indica cultivar, Jaya; and (4) exploring the resistance mechanisms of the new $\mathrm{BPH}$ resistance gene.

\section{Results}

BPH bioassay and genetic analysis of the parental lines and mapping population

To evaluate the resistance strength and spectrum of the donor variety CR2711-76, we conducted the BPH bioassay using different BPH populations of the Philippines representing three biotypes, biotype 1, 2 and 3 duirng 2013-2015 and BPH biotype 4 in 2009, 2010, 2011, 2013, and 2014 in India. For comparisons with the existing popular $\mathrm{BPH}$ resistance sources, Rathu Heenati (BPH3 and BPH17 donor) and PTB-33 (BPH2 and BPH3 donor) were included. The variety CR2711-76 showed strong resistance, as much as the resistant check lines Rathu Heenati and PTB-33, against both BPH biotype 4 and Laguna BPH populations (Table 1). These results indicated that the new BPH resistance source, CR2711-76, had strong and broad-spectrum resistance. The $F_{1}$ plants from the cross between Jaya and CR2711-76 showed strong resistance to both BPH biotype 4 and Laguna $\mathrm{BPH}$ populations suggesting that the resistance was conferred by a dominant genetic factor (Table 1).

The genetic analysis was performed using approximately $3800 \mathrm{~F}_{3}$ plants derived from $151 \mathrm{~F}_{2}$ plants, total of $39 \mathrm{~F}_{3}$ families were susceptible, 85 families were segregating, and 27 families were resistant. The $\mathrm{F}_{2}$ population showed a 1:2:1 $\left(\chi_{(0.11)}^{2}=4.29\right)$ genotypic segregation 
Table $1 \mathrm{BPH}$ reaction score of parents, $\mathrm{F}_{1}$, and check varieties against biotype 4 and Laguna BPH colony

\begin{tabular}{llll}
\hline Genotypes $^{\text {a }}$ & Number of seedlings tested & Average resistance score $^{\text {Significance }^{\mathrm{b}}}$ \\
\hline Reaction to BPH biotype 4 (2009-2014) & & & \\
CR2711-76 & 201 & 2.33 & $\mathrm{a}$ \\
Jaya & 207 & 7.99 & $\mathrm{~b}$ \\
F1 $_{1}$ (Jaya/CR2711-76) & 52 & 1.33 & $\mathrm{a}$ \\
PTB-33 & 206 & 4.03 & $\mathrm{a}$ \\
Reaction to Laguna BPH colony (2013-2015) & & $\mathrm{b}$ \\
CR2711-76 & 199 & 3.87 & $\mathrm{a}$ \\
Jaya & 176 & 8.91 & $\mathrm{~b}$ \\
F1 (Jaya/CR2711-76) & 24 & 2.88 & $\mathrm{~b}$ \\
Rathu Heenati & 210 & 3.11 & $\mathrm{a}$ \\
TN-1 & 272 & 9.01 & \\
\hline
\end{tabular}

TN-1 and Jaya were used as susceptible checks and PTB-33 and Rathu Heenati were used as resistant checks

${ }^{\mathrm{b}}$ Least significant difference test at $\mathrm{a}<0.01$

ratio and 3:1 (124R:27S) phenotypic segregation ratio. In addition to this, mode of inheritance was also analysed using another set of $\mathrm{F}_{2}, \mathrm{BC}_{1} \mathrm{~F}_{1}$ and $\mathrm{BC}_{2} \mathrm{~F}_{2}$ populations consisting of 168, 101 and 249 individuals and the segregation ratio of 3:1, 1:1 and 3:1 (R: S) respectively (Table 2) was obtained. The segregation pattern from these results indicated that $\mathrm{BPH}$ resistance derived from the donor CR2711-76 was controlled by a single dominant gene.

\section{Mechanisms of BPH resistance}

To reveal the resistance mechanisms such as antibiosis, antixenosis, and tolerance of BPH resistant donor, CR2711-76, several experiments were conducted along with Jaya, and several known BPH-resistant lines. Firstly, the antibiosis mechanism was assessed through nymph survival data. The average nymph survival rate was the highest in Jaya (98.66\%), followed by $\mathrm{TN}-1$ (95.45\%). The lowest nymph survival was observed in CR2711-76 $(87.92 \%)$ and it was in the same group as the BPHresistant lines PTB-33 (85.70\%) by DMRT statistical analysis (Fig. 1a). This result indicated that CR2711-76 possessed the antibiosis resistance mechanism. In addition, the area of honeydew secretion as feeding rate was also measured to study the antibiosis on feeding rate mechanism. Our results showed that the average area of honeydew secreted for CR2711-76 $\left(10.33 \mathrm{~mm}^{2}\right)$ was significantly lower than the Jaya $\left(352.71 \mathrm{~mm}^{2}\right)$ (Fig. 1b). We also measured the dry weight of adult female gravids as a feeding rate indicator. Two independent experiments on dry body weight of adult female gravids of Laguna $\mathrm{BPH}$ populations revealed that the lowest body weight of $7.25 \mathrm{mg}$ was observed on the $\mathrm{BPH}$ female gravids, which fed on cultivar CR2711-76, followed by Rathu Heenati and PTB-33 with $8.31 \mathrm{mg}$ and $8.80 \mathrm{mg}$, respectively. The highest body weight was recorded in the female gravids that fed on TN-1, followed by near isogenic lines (NIL), NIL-BPH3, NIL-QBPH4 and QBPH6 with $12.07 \mathrm{mg}$, $11.37 \mathrm{mg}$, and $10.44 \mathrm{mg}$, respectively. $\mathrm{BPH}$ fed more on TN-1, NIL-BPH3, NIL-QBPH4, and QBPH6 than on CR2711-76, Rathu Heenati, and PTB-33 (Fig. 1c). These three different assays (antibiosis on nymph survival rate, feeding rate on area of honey dew and $\mathrm{BPH}$ body weight) strongly support that CR2711-76 has the antibiosis mechanism for $\mathrm{BPH}$ resistance.

To test the antixenosis mechanism, the number of $\mathrm{BPH}$ insects was monitored on the different genotypes for 9 days after $\mathrm{BPH}$ infestation, when there was $90 \%$ TN-1 wilted. There was a significant decrease in the number of insects in the resistant lines, CR2711-76 (20.85 to 8.97) and Rathu Heenati (14.96 to 9.08) while $\mathrm{BPH}$ nymphs significantly increased in the susceptible lines, Jaya (6.83 to 18.88 ) and TN-1 (8.89 to 19.67). On

Table 2 The genetic analysis of different maping populations derived from Jaya $\times$ CR2711-76 cross evaluated against BPH

\begin{tabular}{|c|c|c|c|c|c|c|}
\hline Mapping population type & Resistant plants (No.) & Susceptible plants (No.) & Total plants (No.) & Segregation (R:S) & $x^{2}$ & a value \\
\hline${ }^{a} F_{2}$ (1st set) & 123 & 28 & 151 & $3: 01$ & 3.35 & 0.06 \\
\hline${ }^{a} F_{2}$ (2nd set) & 131 & 37 & 168 & 3:01 & 0.79 & 0.37 \\
\hline${ }^{\mathrm{a}} \mathrm{BC}_{1} \mathrm{~F}_{1}$ & 55 & 46 & 101 & 1:01 & 0.8 & 0.37 \\
\hline${ }^{\mathrm{b}} \mathrm{BC}_{2} \mathrm{~F}_{2}$ & 181 & 68 & 249 & 3:01 & 0.7 & 0.4 \\
\hline
\end{tabular}

a BPH biotype 4

${ }^{\mathrm{b}}$ Laguna BPH population 


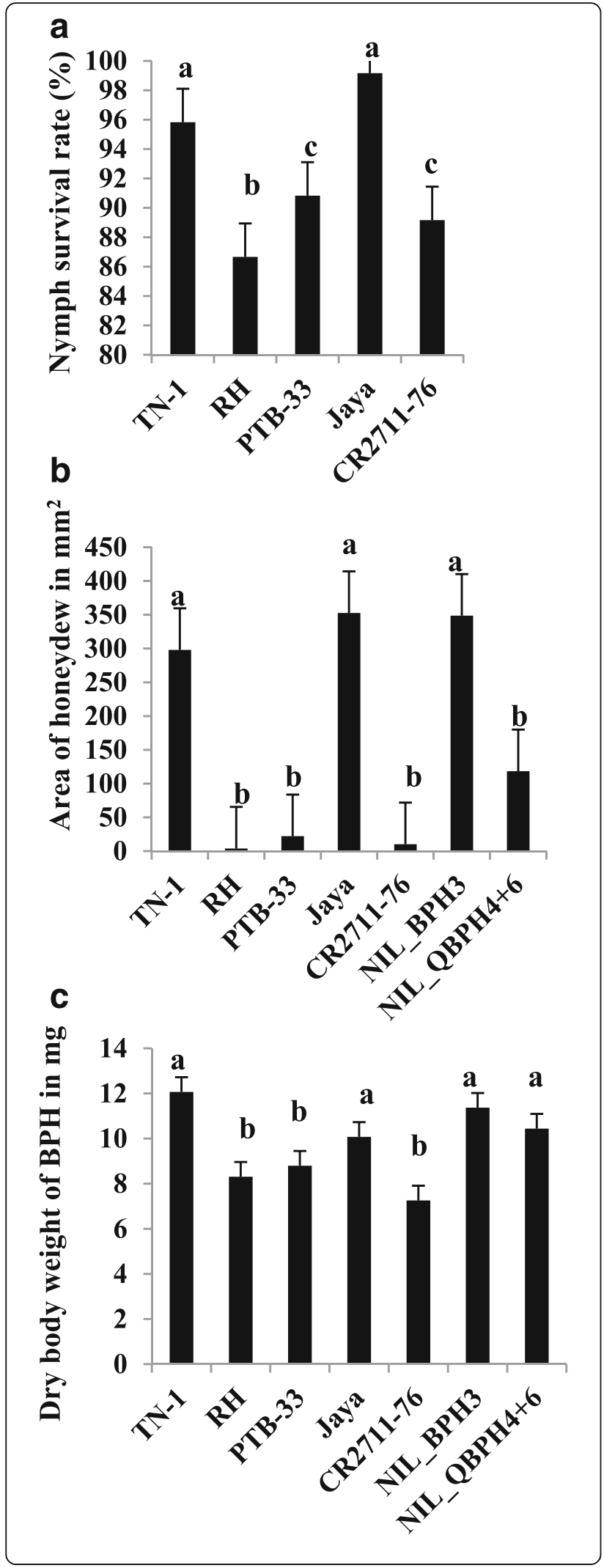

Fig. 1 Antibiosis mechanism tests. a Nymph survival rate of different test lines. $\mathbf{b}$ Area of honeydew secretion as the parameter of antibiosis on feeding rate. $\mathbf{c}$ Dried body weight of BPH female gravids as the parameter of antibiosis on feeding rate. Error bar represents the standard error of different replications

the ninth day after $\mathrm{BPH}$ infestation, significant difference in the total load of BPH nymphs on the CR2711-76 (8.97) and Jaya (18.88) was observed (Additional file 8: Figure S8). This result clearly indicated that, CR2711-76 possess the antixenosis mechanism of resistance (Fig. $2 \mathrm{a}$ and b). However, for NIL-BPH3 and NIL-BPH17, no significant difference was observed with respect to the number of $\mathrm{BPH}$ per hill for 9 days.

To analyze the tolerance mechanism of the cultivars, the functional plant loss index (FPLI) and tolerance index (TI) were calculated. TI was observed to be the lowest in PTB-33, followed by Rathu Heenati and CR2711-76, with TI values of $0.13,0.48$, and 0.50 , respectively. No significant difference was observed among the TI values of Jaya and TN-1, indicating that they were on par with the tolerance mechanism (Fig. 2c). To analyze FPLI, a regression line was generated from the regression of FPLI on the dry weight of $\mathrm{BPH}$ and the mean dry weight of $\mathrm{BPH}$ divided the graph into four quadrants (sectors). As expected, Jaya and $\mathrm{TN}-1$, with high body weight of BPH and high FPLI values, congregated in the low tolerance and low antibiosis (susceptible) quadrant. PTB-33, with high FPLI value and low $\mathrm{BPH}$ body weight, congregated in the high antibiosis and low tolerance quadrant. However, Rathu Heenati and CR2711-76, with lower BPH body weight and low FPLI, congregated in the high tolerance and high antibiosis quadrant. This experiment of tolerance segregated the resistant varieties with different mechanisms of resistance (Fig. 2d). From this experiment, it was evident that CR2711-76 possesses a tolerance mechanism to provide resistance for a long period of time (Table 1).

\section{Broad-spectrum resistance of the CR2711-76}

The resistance spectrum of CR2711-76 was tested by measuring the honeydew secretion area against the three different $\mathrm{BPH}$ populations that were collected in the three different provinces (Isabela, Bicol, and Nueva Ecija) in the Philippines. For the Isabela BPH populations, the highest and the lowest honeydew secretion area were observed on TN-1 $\left(846.41 \mathrm{~mm}^{2}\right)$ and CR2711-76 (84.69 $\left.\mathrm{mm}^{2}\right)$, respectively (Additional file 1: Figure S1a). For Bicol BPH populations, the highest honeydew secretion area was noticed in $\mathrm{TN}-1$ $\left(536.74 \mathrm{~mm}^{2}\right)$, followed by Jaya $\left(502.61 \mathrm{~mm}^{2}\right)$, whereas the lowest honeydew secretion area was observed in CR2711-76 (103.27 $\left.\mathrm{mm}^{2}\right)$ (Additional file 1: Figure S1b). Interestingly, honeydew secretion was completely absent 

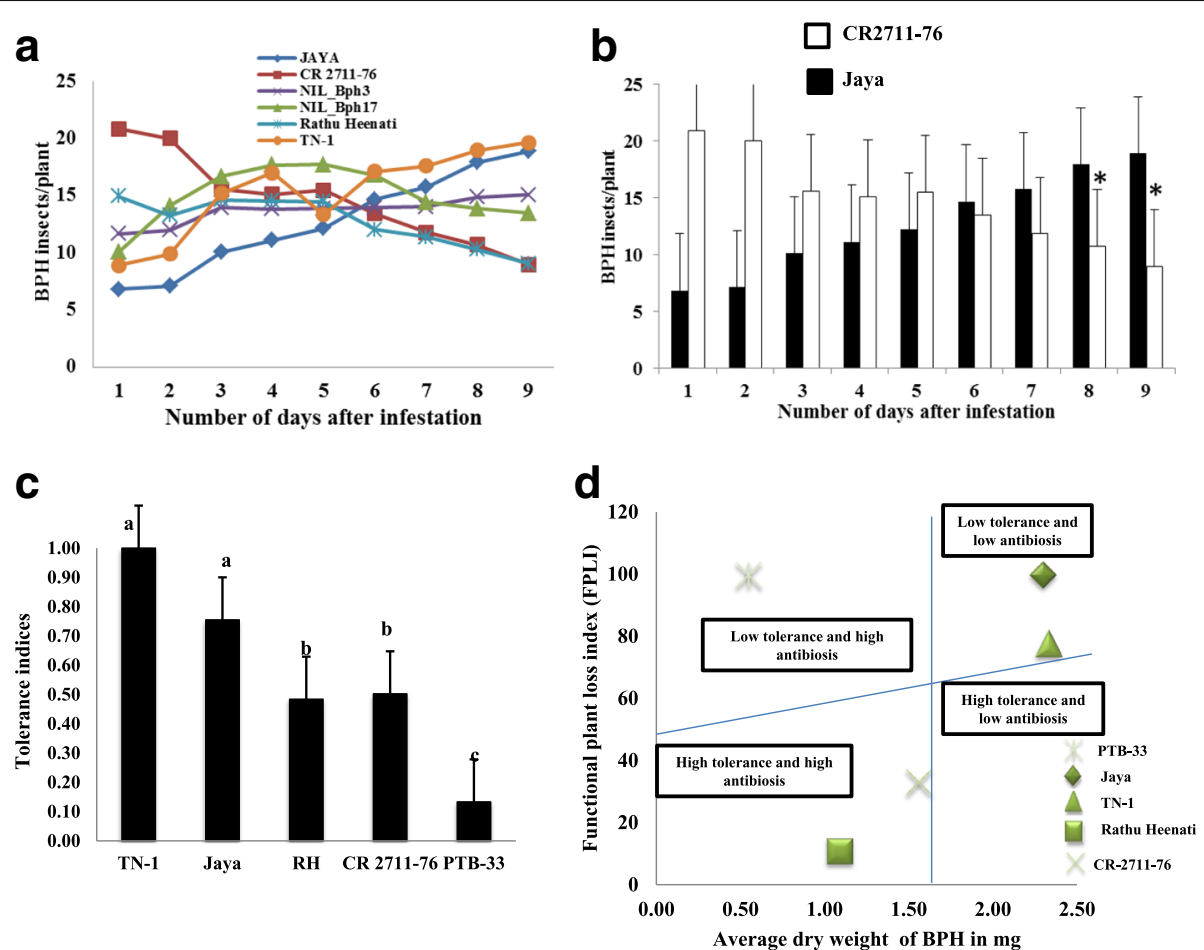

Fig. 2 Antixenosis and tolerance mechanism tests. a Non-preference behavior of BPH adults for different test genotypes at the different days after infestation with each colored lines indicating different genotypes. b Non-preference behavior of BPH nymphs for parental lines, Jaya and CR2711-76; error bars indicate the standard error of standard deviation of three replications. c Tolerance indices of test lines. $\mathbf{d}$ FPLI graph showing the differentiation of antibiosis and tolerance mechanisms of resistance to BPH. Letters $a, b, c$ indicate DMRT significance values $(a=0.01)$

in CR2711-76 and $F_{1}$ generated from the cross of Jaya $x$ CR2711-76 when Nueva Ecija BPH adults fed on this line (Additional file 1: Figure S1c; Additional file 2: Figure S2). In addition to this, antibiosis (seedling survival rate) of parental lines and $F_{1} s$ was also carried out to study the broad spectrum resistance of CR2711-76 in both India and the Philippines respectively. The significant difference in resistance score between CR2711-76 (resistant; 2.33 and 3.87) and Jaya (susceptible; 7.99 and 8.91) was observed when they were screened for both Indian and Philippines $\mathrm{BPH}$ colony during 2009-2014 and 2013-2015 respectively (Table 1). This result of antibiosis reaction of CR2711-76 against different $\mathrm{BPH}$ populations of the Philippines and India strongly support that, it possess broad-spectrum resistance.

\section{Inheritance of antibiosis on feeding rate}

The inheritance of the resistance gene derived from CR2711-76 for BPH colonies of Laguna and Nueva Ecija was studied by assessing the antibiosis on feeding rate. The area of honeydew secreted was $31.39 \mathrm{~mm}^{2}$ after Laguna BPH colony fed on CR2711-76. It was smallest $\left(4.78 \mathrm{~mm}^{2}\right)$ and completely absent after Laguna and Nueva Ecija BPH populations fed on $F_{1}$ plants respectively (Additional file 1: Figure S1d). This result showed that the $\mathrm{BPH}$ resistance is a dominance type of genetic factor.

\section{Linkage map construction and localization of a resistance gene}

To identify the $\mathrm{BPH}$ resistance locus of the $\mathrm{BPH}$ resistant donor line, CR2711-76, PCR genotyping was performed using $151 \quad \mathrm{~F}_{2}$ genomic DNAs with 107 polymorphic markers distributed over the entire rice genome. The mapping population was successively genotyped with all the 107 anchored markers, and a linkage map was constructed (Additional file 3: Figure S3). All the anchored markers on the framework map (linkage map skeleton) were tested for linkage relationships and a $\mathrm{BPH}$ resistance factor was initially localized on the long arm of chromosome 3 between the SSR markers RM251 and RM2334 through QTL analysis using QTL IciMapping software (Additional file 4: Figure S4a) spanning a region of $24.30 \mathrm{cM}$ under extreme linkage criteria with a minimum LOD score of 11 at 1000 permutations. Only a single major locus from CR2711-76 present on the chromosome 3 was identified throughout 12 chromosomes which was consistent with our previous genetic analysis data suggesting three different mechanisms of resistance. The result was validated using WinQTL Cartographer and a similar result was retrieved (Additional file 4: Figure S4b). The 
putatively identified new resistance gene was named as BPH31 (Additional file 10: Figure S10).

\section{Fine mapping and candidate gene identification at the $B P H 31$ locus}

For fine mapping of the BPH31 locus, 27 InDel markers were newly designed based on primary mapping results (Additional file 11: Table S1) and tested in the parents. Four markers showed polymorphism and these InDel markers were used to screen the same $F_{2}$ population with 151 individuals and linkage analysis was further carried out. Finally, the putative resistance gene, BPH31, was located between the markers PA26 and RM2334 with a LOD score of 47.64 and $79.8 \%$ phenotypic variance. The physical size of the genetic locus between markers PA26 and RM2334 was $475 \mathrm{~kb}$ based on the Nipponbare reference genome in the TIGR database (Fig. 3a-d).

Genome annotation data of the fine-mapped BPH31 locus (475 kb region) contained minimum of 42 candidate genes (Additional file 12: Table S2). We examined the putative functions of all 42 candidate genes using the BPLAST-P tool and it was revealed that three genes (LOC_Os03g46440, LOC_OsO3g46454, and LOC_OsO3g46550) might be associated with biotic stress stimulus. Among the three putative candidate genes, LOC_OsO3g46550 encodes LRR domain protein, which is found in many defense-related genes. In addition, in silico gene expression analysis in the Rice oligo nucleotide array and RiceXPro data base showed that LOC_Os03g46550 gene preferentially expressed in the thirdto fourth-leaf stage (Additional file 5: Figure S5a-c), when maximum infestation of $\mathrm{BPH}$ insect was observed.

\section{Validation of $B P H 31$ flanking marker for MAS}

The efficacy of the markers within the primary mapped locus was tested using the $\mathrm{BC}_{2} \mathrm{~F}_{2}$ population derived from the cross Jaya $\times$ CR2711-76. This was performed by genotyping (using the flanking markers of $B P H 31$ ) and phenotyping the homo and heterozygous plants derived $\mathrm{BC}_{2} \mathrm{~F}_{2}$ progenies. As expected, homozygous recessive $\mathrm{BC}_{2} \mathrm{~F}_{2}$ plants showed a high susceptibility reaction to $\mathrm{BPH}$ while $\mathrm{BC}_{2} \mathrm{~F}_{2}$ plants showed segregation in the $\mathrm{BPH}$ resistance reaction (Additional file 6: Figure S6). The seedling survival rate and SES score of $149 \mathrm{BC}_{2} \mathrm{~F}_{2}$ plants and flanking markers of fine-mapped $B P H 31$ genotype data were compared to analyze the percent co-segregation. The markers PA25, PA26 and RM2334 were showed high co-segregation with the $\mathrm{BPH}$ reaction. Among these markers, PA26 and RM2334 showed highest co-

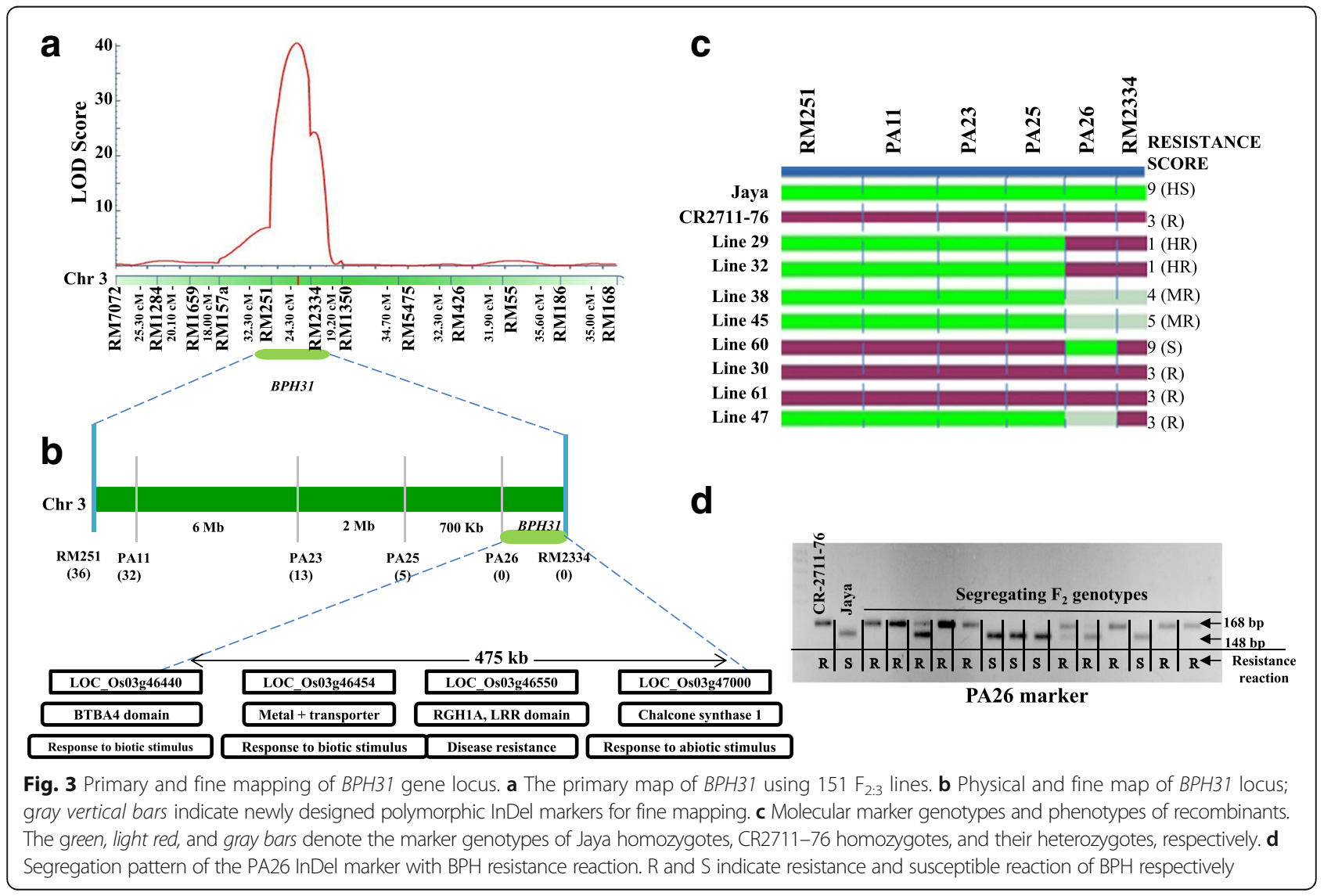


segregation. Hence, these markers were considered as tightly linked markers and used for introgressing $B P H 31$ in the background of Jaya.

\section{Marker-assisted introgression of $B P H 31$}

Based on the genotype of flanking markers, RM251, PA26, and RM2334 of the BPH31 locus, $101 \mathrm{BC}_{1} \mathrm{~F}_{1}$ individuals were subjected to foreground selection. Of the $101 \mathrm{BC}_{1} \mathrm{~F}_{1} \mathrm{~s}, 41 \mathrm{BC}_{1} \mathrm{~F}_{1}$ plants were found to have $\mathrm{BPH} 31$, whereas 60 individuals were negative for the presence of the $B P H 31$ gene. These $41 \mathrm{BC}_{1} \mathrm{~F}_{1}$ plants were selected for background analysis and phenotypic selection for improving Jaya.

Selected individuals of $\mathrm{BC}_{1} \mathrm{~F}_{1} \mathrm{~s}$ with the $\mathrm{BPH} 31$ resistance gene were backcrossed to recipeient cultivar, Jaya to produce $\mathrm{BC}_{2} \mathrm{~F}_{1}$ plants. Background genotyping analysis by high-density SNP markers revealed a significant quantity of recurrent parent genome recovery and the BPH31 introgression from the donor parent at its respective locus (Fig. 4). Phenotypic selection was also practiced to select genotypes with superior agronomic traits. The selected individuals were superior in agronomic traits such as larger panicle length (ranging from $18.40 \mathrm{~cm}$ to $26.50 \mathrm{~cm}$ ) and higher grain yield per plant than the original recurrent parent, Jaya. However, the grain type was similar to Jaya (Table 3 ).

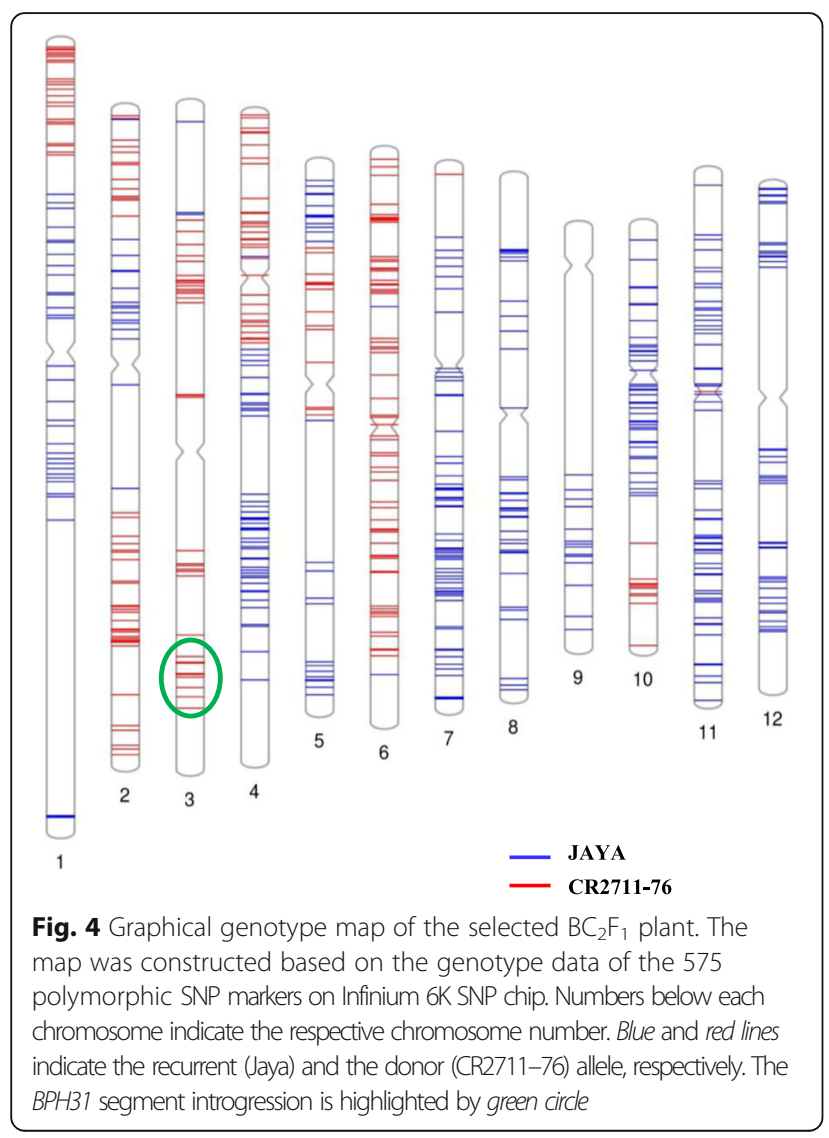

\section{Discussion}

$\mathrm{BPH}$ is the most devastating pest of the rice crop and severe infestation causes "hopper burn" symptom in rice fields, resulting in complete death of rice plants. This pest causes serious problems in rice production worldwide, especially in Asia. Among the four classified different biotypes of $\mathrm{BPH}$, biotype 4 is the most damaging and prevalent insect pest in South Asian countries, especially on the Indian subcontinent. Only a few resistance genes are available for providing resistance against this biotype 4. Hence, it is essential to identify and characterize new $\mathrm{BPH}$ resistance genes for stable rice production. Because only the identification of the sources of resistance genes is not sufficient to use in breeding, it is necessary to locate the gene and identify the tightly linked molecular markers for the gene. Additionally, BPH resistance genes act in different ways to keep the plant healthier. In a suitable $\mathrm{BPH}$ resistance breeding program, it will be necessary to know the mode of gene action to pyramid the right combinations of genes. Using location/linked markers and considering their mode of action, the resistance gene has to be introgressed into $\mathrm{BPH}$-susceptible elite rice cultivars for sustainable rice production. In this study, we identified a strong broad-spectrum BPH resistance gene, BPH31 and fine-mapped the gene on the long arm of chromosome 3. The analysis on the mode of gene action revealed interesting results: that the gene had all the three different kinds of resistance mechanisms (antibiosis, antixenosis, and tolerance) against $\mathrm{BPH}$ insects. To prove the applicability of the new BPH31 gene in a BPH resistance breeding program, the gene was successfully introgressed into an elite indica cultivar (Jaya) using the tightly linked InDel marker PA26 and RM2334.

The BPH resistance source was an indica rice cultivar, CR2711-76. This cultivar was selected as a donor for the $\mathrm{BPH}$ resistance gene identification program as it had been providing resistance for the last seven consecutive years in our evaluation experiments in the region, which was prone to severe $\mathrm{BPH}$ infestation. Irrespective of the $\mathrm{BPH}$ infestation pressure, CR2711-76 provides strong $\mathrm{BPH}$ resistance, which indicates that it possesses a strong and broad-spectrum BPH resistance gene.

Understanding the mechanisms underlying resistance to $\mathrm{BPH}$ is essential for developing appropriate breeding strategies (Qiu et al. 2012). Hence, we have also explored all three kinds of mechanisms (antibiosis, antixenosis, and tolerance) underlying BPH resistance.

Antibiosis on nymph survival studies revealed that BPH nymphs feeding on CR2711-76 showed a high mortality rate in contrast to Jaya and susceptible check TN-1. The DMRT results clearly indicated that CR2711-76 possesses antibiosis on nymph survival against Laguna BPH populations compared to Jaya with low nymphal mortality. Hence, CR2711-76 can be used for developing a cultivar that can 
Table $\mathbf{3}$ List of genotypes with agronomically important traits

\begin{tabular}{|c|c|c|c|c|}
\hline No. & Genotypes & Grain type & Panicle length $(\mathrm{cm})$ & Grain yield per plant (g) \\
\hline 1 & Jaya & long bold & $22.80^{\mathrm{a}}$ & $17.10^{\mathrm{a}}$ \\
\hline 2 & CR2711-76 & short bold & $19.70^{\mathrm{a}}$ & $13.06^{\mathrm{a}}$ \\
\hline 3 & BC1F1-3-BC2F1-1-1-110 & short bold & 20.50 & 14.36 \\
\hline 4 & BC1F1-5-BC2F1-2-1-133 & long bold & 25.50 & 19.15 \\
\hline 5 & BC1F1-32-BC2F1-7-1-167 & medium bold & 24.30 & 14.40 \\
\hline 6 & BC1F1-42-BC2F1-13-1-250 & medium bold & 21.70 & 13.88 \\
\hline 7 & BC1F1-32-BC2F1-7-12-166 & long bold & 22.00 & 18.66 \\
\hline 8 & BC1F1-54-BC2F1-17-11-291 & short bold & 18.40 & 16.76 \\
\hline 9 & BC1F1-40-BC2F1-11-2-215 & short bold & 22.50 & 9.11 \\
\hline \multirow[t]{7}{*}{10} & BC1F1-35-BC2F1-8-7-176 & long bold & 26.50 & 18.50 \\
\hline & & Mean & 22.39 & 15.50 \\
\hline & & Standard error & 0.80 & 0.99 \\
\hline & & Range & 8.10 & 10.04 \\
\hline & & Minimum & 18.40 & 9.11 \\
\hline & & Maximum & 26.50 & 19.15 \\
\hline & & Confidence level (95.0\%) & 1.81 & 2.24 \\
\hline
\end{tabular}

${ }^{\mathrm{a}}$ Indicates average values of each observation

reduce $\mathrm{BPH}$ load in the field at the nymphal stage of insect attack. The area of honeydew secreted and the dry body weights of BPH female gravids are the parameters for measuring the antibiosis on feeding rate. The area of honeydew secreted when BPH feeds on Rathu Heenati was the lowest, followed by CR2711-76 and PTB-33, in the first experiment. This experiment revealed that $\mathrm{BPH}$ female gravids fed very low phloem sap or no phloem sap from the resistant cultivars (CR2711-76, Rathu Heenati, and PTB-33) compared to $\mathrm{TN}-1$ and Jaya, on which they feed more phloem sap, and therefore they exuded more honeydew, which was witnessed as a blue color stain on the bromocresol green treated filter paper (Heinrichs et al. 1985). In addition, the difference in the feeding behavior of the Rathu Heenati and NIL-BPH3 test lines was noticed. This could be because, Rathu Heenati also possess another major BPH resistance gene $B P H 17$ (Sun et al., 2005) and other BPH resistance QTLs, qBPH3, qBPH4 and $q B P H 10$ (Acc.no. 11730; Sun et al. 2005) and other reason could be due to background effect of the NIL. Furthermore, the oven-dry body weight of BPH adults was also the lowest in CR271176, followed by Rathu Heenati and PTB-33, meaning that CR2711-76 allowed BPH female gravids to consume very low amounts of plant biomass, followed by Rathu Heenati and PTB-33 (Pathak and Heinrichs 1982). It should be noted that antibiosis on feeding rate in terms of body weight of BPH on CR2711-76 showed a strong antibiosis mechanism of resistance, followed by Rathu Heenati and PTB-33. Hence, based on these results, it can be concluded that, CR2711-76 possesses a strong antibiosis mechanism on feeding rate of $\mathrm{BPH}$ resistance against Laguna populations when compared with PTB-33, which is the Indian national resistant check for biotype 4 . It is noteworthy to mention that, honeydew secretion was completely absent in both CR2711-76 and $F_{1}$ derived from the cross of Jaya $\times$ CR2711-76, suggesting the complete dominance reaction of resistance gene $B P H 31$ to $\mathrm{BPH}$ for the Nueva Ecijia BPH populations. Hence, CR2711-76 possessing BPH31 has a strong antibiosis resistance mechanism. In testing antixenosis, the BPH load decreased after 2 days of infestation and the BPH load was lowest in Rathu Heenati and CR2711-76 on the ninth day after infestation, whereas BPH load was highest in Jaya, followed by TN-1. This result showed that BPH nymphs refused to feed on CR2711-76 and Rathu Heenati and, hence, they moved and settled on susceptible lines (non-preference). Thus, CR2711-76, as a resistance gene donor, possesses an antixenosis mechanism and is not allowing BPH to settle and feed on it unlike Jaya which was highly preferred by BPH insects.

The tolerance mechanism of the resistance results showed the significant difference in the tolerance level among the different BPH resistant lines (CR2711-76, PTB-33 and Rathu Heenati) and cultivar CR2711-76 with the $B P H 31$ gene has exhibited a high level of tolerance mechanism (Fig. 2d). This study explains that CR2711-76 has a broad-spectrum of resistance with antibiosis, antixenosis, and tolerance mechanisms to different BPH populations of the Philippines and BPH biotype 4 of India. It has been well understood that those varieties or cultivars that possess all three kinds of mechanisms of resistance often show broad-spectrum and stable resistance for a long period of time (Panda 
and Heinrichs 1983). If the antibiosis and antixenosis mechanisms of resistance genes are overcome by the insect, the tolerance mechanism can work as a second line of defense that may continue to function (Mackenzie 1980). In support, the bioassay results from 2009 to 2014 in India and 2013-2015 in the Philippines ( $\sim 7$ years) proved that, CR2711-76 is stable resistant cultivar (Additional file 9: Figure S9 and Table 1). Hence, CR2711-76 can be considered as a new donor for broadspectrum resistance to different $\mathrm{BPH}$ populations of the Philippines such as Laguna, Isabela, Bicol, and Neuva Ecijia which belongs to three different BPH biotypes, biotype 1, 2 and 3 (Saxena and Barrion 1985) and Indian biotype 4. Similar to this study, IR64 also has all three mechanisms of resistance (antibiosis, antixenosis, and tolerance) and sustained moderate resistance for quite a long period of time (Cohen et al. 1997).

Thirty BPH resistance genes have been reported to date (Deen et al. 2017). Many of these BPH resistance genes identified showed resistance against biotype 1 and 2 are not effective against biotype 4 (Deen et al. 2010). Advances in molecular biology and the availability of recent new molecular genomics approaches have paved the way to the identification and fine mapping of many $\mathrm{BPH}$ resistance genes going from BPH18 in 2006 to $B P H 32(t)$ in 2016 (Cha et al. 2008; Sun et al. 2006; Qiu et al. 2010; Zhao et al. 2016; Qiu et al. 2012; Du et al. 2009; Lv et al. 2014; Jena et al. 2006; Chen et al. 2006; Myint et al. 2012; Tamura et al. 2014; Huang et al. 2013; Wu et al. 2014; Wang et al. 2015; Ren et al. 2016). For the resistance gene $B P H 31$, the initial genetic locus size was around $16 \mathrm{Mb}$ and, hence, the chance of recombination between the genetic locus and the markers was high. We applied a fine-mapping approach to narrow down and reduce the gene-marker recombination. Based on the information available on rice genome sequences and putative functions involved in $\mathrm{BPH}$ resistance or biotic stress stimulus in 3000 genome sequences at IRRI, in the OryzaSNP database, and in Nipponbare genomic sequences available in the MSU database by the prediction method, we designed putative linked markers for BPH31 (Additional file 11: Table S1). Of the 27 InDel markers designed at regular intervals, four were polymorphic and these markers were used for linkage analysis using $151 \mathrm{~F}_{2: 3}$ mapping populations similar to the earlier approaches (Jena et al. 2006; He et al. 2013; Wu et al. 2014). Linkage analysis was further carried out to find closely linked DNA markers for BPH31. Finally, the BPH31 gene was located in between the markers PA26 and RM2334, which have $79.8 \%$ phenotypic variance at LOD 47.64, and the size of the locus was $475 \mathrm{~kb}$. For the mapping experiments, marker and phenotype data were analyzed using QTL IciMapping software ver. 4.0 (Meng et al. 2015) and confirmed with WinQTL Cartographer ver 2.5 (Wang 2012). The derived results and gene location were similar in all the analyzed tools, indicating the high reliability of the results and experiments conducted. To our knowledge, no BPH resistance gene has been reported in the chromosomal region of the BPH31 locus. However, BPH13 gene was localized on the same chromosome 3 and, hence, we evaluated their resistance reaction in comparison with that of $B P H 31$. This gene was significantly differing in its resistance reaction and the mechanism of resistance as shown in Additional file 1: Figure S1a and $\mathrm{b}$. The genomic fragment of the BPH31 locus contains minimum of 42 putative genes, of which three candidate genes (LOC_Os03g46440, LOC_OsO3g46454, and LOC_ Os03g46550) are found to be near the closely linked marker PA26. Gene expression of these genes was studied using online data bases including RiceXPro. This data base retrives transcriptome analysis of different candidate genes (LOC_Os03g46440, LOC_Os03g46454, and LOC_Os 03g46550) which were already deposited (Sato et al. 2013). the result from this analysis showed that these genes were involved in biotic stimulus functions. Especially, the gene LOC_Os03g46550 encodes the LRR domain, which was reported to be involved in $\mathrm{BPH}$ resistance for four of the seven $\mathrm{BPH}$ resistance genes including BPH18 (Du et al. 2009; Tamura et al. 2014; Liu et al. 2015; Ji et al. 2016) and close to the flanking marker which showed high cosegregation. This gene found expressing at the early seedling stage like other BPH resistance genes. Similarly, the BPH 31 locus may also lie in the cluster of three candidate genes conferring $\mathrm{BPH}$ resistance. Alternatively, one of the three genes may act independently for BPH resistance. However, this needs further study for confirmation (Additional file 13: Table S3).

Jaya is one of the commercially cultivated rice varieties in Southern India but it is highly susceptible to BPH. We selected Jaya for improving BPH resistance through transfer of the new CR2711-76 - derived BPH31 gene in a resistance breeding program using the tightly linked markers PA26 and RM2334. Therefore, the present study focused on improving Jaya by introgressing BPH31 through marker-assisted backcrossing. Agronomic traits of the improved lines were taken care of as Jaya was preferred by farmers and consumers for its grain quality. The results on agronomic performance showed that introgressed lines were superior for panicle length and grain yield per plant to Jaya while grain characteristics similar to Jaya.

\section{Conclusion}

The present study identified a new, broad-spectrum $\mathrm{BPH}$ resistance gene, $B P H 31$ that was located on the long arm of chromosome 3 by linkage analysis and finemapping strategies. This gene not only showed a consistent resistance reaction to Indian BPH biotype 4 but also resistance to several $\mathrm{BPH}$ populations collected in The 
Philippines. This study also revealed that the BPH31 gene had all three BPH resistance mechanisms responsible for broad-spectrum resistance. The applicability of the gene and the linked markers (PA26 and RM2334) showed promise through introgression lines obtained in the indica rice cultivar Jaya background through MAS. We believe that the improved variety Jaya will facilitate managing BPH problems in Southern India. The BPH31 gene and the tightly linked InDel type markers can be used in any other BPH resistance breeding programs toward developing rice cultivars with broad-spectrum $\mathrm{BPH}$ resistance on the Indian subcontinent.

\section{Methods}

\section{Plant materials}

The variety CR2711-76 developed by NRRI, Cuttack, India, was used as a donor material for the identification of a new BPH resistance gene. A BPH-susceptible variety, Jaya, was used as the recipient parent. A set of 13 BPH NILs, (NIL-BPH2, NIL-BPH3, NIL-BPH4, NILQBPH4 + QBPH6, NIL-BPH9, NIL-BPH10, NIL-BPH17, NIL-BPH18, NIL-BPH20, NIL-BPH21, NIL-BPH25, NIL$B P H 26$, and NIL-BPH25 + BPH26) and the BPH13 donor line were developed and maintained in the Novel Gene Resources (NGR) laboratory, Plant Breeding Division of IRRI (Jena et al. unpublished data). These NILs were used to comparatively assess the resistance/susceptible reactions of the new resistance gene with already reported genes and to assess the differences in mechanism of resistance. PTB-33 and Rathu Heenati were used as BPH-resistant checks while Taichung Native-1 (TN-1) and Jaya were used as susceptible check cultivars. The detected gene in the present study was designated as $B P H 31$ because this gene was detected during 2015. At that time only $30 \mathrm{BPH}$ reistance genes were identified and designated. Since this was the new gene, it was designated as $B P H 31$ after $B P H 30$ which was later considered by Ren et al. 2016 and hence, they named their gene as $B P H 32$.

\section{Development of mapping populations}

A cross between the resistant variety CR2711-76 and Jaya was made and $F_{1}$ plants were produced. The true $F_{1}$ plants were selfed and they produced $F_{2}$ seeds. In addition, the $\mathrm{F}_{1}$ plants were further backcrossed to the recurrent parent Jaya to generate $\mathrm{BC}_{1} \mathrm{~F}_{1}$ seeds. A total of $151 \mathrm{~F}_{2}$ and $\mathrm{BC}_{1} \mathrm{~F}_{1}$ plants were genotyped and were selfed to generate $F_{3}$ and $B C_{1} F_{2}$ progenies, respectively. The $F_{3}$ plants were phenotyped for $\mathrm{BPH}$ resistance or susceptibility. Foreground selection was practiced to generate $\mathrm{BC}_{2} \mathrm{~F}_{1}$ progenies after backcrossing with Jaya as the recurrent parent, based on the identified gene flanking marker genotype data. Phenotypic selection and background analysis were performed to generate $\mathrm{BC}_{3} \mathrm{~F}_{1}$ plants \{introgressed lines (ILs)\} that possessed the new $\mathrm{BPH}$ resistance gene. To confirm their resistance and to validate the co-segregation of the newly developed markers, $\mathrm{BC}_{2} \mathrm{~F}_{1}$ plants were selfed and the $\mathrm{BC}_{2} \mathrm{~F}_{2}$ plants were used for marker validation (Additional file 7: Figure S7).

\section{BPH population and bioassay for resistance}

A pure BPH population (biotype 4) was developed from a single colony of BPH and was grown on the susceptible variety Jaya in a cage in Entomology Division of the Zonal Agricultural Research Station (ZARS), V.C. Farm, Mandya, Karnataka, India. The susceptible check variety $\mathrm{TN}-1$ was used for feeding different BPH populations of the Philippines (Isabela, Nueva Ecija, Laguna and Bicol). Four $\mathrm{BPH}$ populations are the representative populations of the Philippines in terms of geographical locations: the Isabela, Nueva Ecijia, Laguna and Bicol provinces belongs to Region II, Region III, Region IV and Region V. These populations are the representative BPH populations of biotype 1, 2 and 3 (Saxena and Barrion 1985). The bioassay was done following the method of Jena et al. (2006) with minor modifications. Seedlings at the two- to three-leaf stage were infested with second- or third-instar nymphs at a density of 10-12 nymphs per seedling. Once the standard susceptible check varieties Jaya and $\mathrm{TN}-1$ started wilting (90\%), data were recorded as seedling survival rate and finally expressed as a standard evaluation system (SES) score (IRRI, 1996). Higher BPH scores indicate susceptibility and the lowest score indicates an immune response of the genotype. For the evaluation of parental lines, a minimum of 25 seedlings were maintained per test entry with three replications. For phenotyping of the mapping population, seedlings of $F_{3}$ families of the $F_{2}$ mapping population (Jaya $\times$ CR2711-76) were planted into randomly selected rows in the glasshouse. Evaluations were based on the degree of susceptibility of the $\mathrm{S}$ check. Genotypes with a BPH response (RR: homozygous resistant, RS: segregating heterozygous, SS: homozygous susceptible) of the $151 \mathrm{~F}_{2}$ individuals were determined by assaying the phenotypes ( $\mathrm{R}$ or $\mathrm{S}$ ) of the corresponding $\mathrm{F}_{3}$ progenies. A complete resistance score $(0-1)$ was given to progenies expressing $91-100 \%$ seedling survival, resistance scores of $2-3$ were for progenies with $76-90 \%$ seedling survival, scores of 4-7 were for progenies with 11-75\% survival, and scores of 8-9 were for progenies with complete susceptibility and $0-10 \%$ survival.

\section{Mechanisms of BPH resistance}

The present study explored all three kinds of resistance mechanisms: antibiosis, antixenosis, and tolerance.

\section{Antibiosis}

The antibiosis mechanism of resistance was measured based on two parameters: antibiosis on nymph survival and antibiosis on feeding rate. 


\section{Antibiosis on nymph survival}

In this method of determining antibiosis mechanism, about 20 pre-germinated seedlings of each cultivar were grown in a $10 \mathrm{~cm}$ diameter clay pot. The pots were randomly placed in a $68 \mathrm{~cm} \times 42 \mathrm{~cm} \times 16 \mathrm{~cm}$ plastic seedbox with about $2 \mathrm{~cm}$ of water maintained in the bottom until completion of the experiment. Seedlings were thinned to 6 per pot 7 days after seeding, and at the thirdleaf stage were infested with 2nd -instar BPH nymphs at the rate of 10 insects per plant. The potted plants were then covered with cylindrical Mylar cages $(13 \times 50 \mathrm{~cm})$. The nymphs per plant were counted 4-day postinfestation. The experiment was repeated twice; 6 individual plants were measured for each cultivar per replicate. Number of nymphs on each plant was finally expressed as nymph survival rate and the genotype which has highest nymph survival rate declared as susceptible after comparing with susceptible and resistant check and vice versa (Heinrichs et al. 1985; Hu et al. 2012).

\section{Antibiosis on feeding rate}

This is another method of determining the level of antibiosis based on the area of honey dew secreted and weight of the BPH insects. The experiment was conducted by following the methodology prescribed by Heinrichs et al. 1985 with slight modifications. Exactly 10 female hoppers (adult gravids) were introduced after starving for 1-1.5 h into each cage through the top of the inverted plastic cup where the stem of the plant passes through. The opening of the cup is plugged with cotton to prevent escape of the insects. Spots on the filter paper are evident as soon as honeydew is excreted. After the hoppers have fed for $24 \mathrm{~h}$, filter papers were removed from the cage. Collected filter paper is placed on A4 size white paper as 2 or 4 filter papers per white paper. A $1 \mathrm{~cm}$ line was drawn on the A4 size white paper at the top of the filter paper this will be used to set scale for measuring the area of spot by using ImageJ software. BPH adults were collected and oven dried for $24 \mathrm{~h}$. After $24 \mathrm{~h}$ oven dried $\mathrm{BPH}$ adult females were weighed in $0.001 \mathrm{mg}$ sensitive weighing balance for estimating body weight.

\section{Antixenosis}

Antixenosis on nymphs on seedlings Another mechanism of resistance, antixenosis, was assayed based on the preference of test lines by the BPH for feeding. This study on the level of antixenosis was conducted simultaneously with the conventional seed box screening test (Heinrichs et al. 1985). The first scoring was recorded after $24 \mathrm{~h}$ of infestation of BPH nymphs at two to threeleaf stages of plants and next scoring was done after every $24 \mathrm{~h}$ for number of $\mathrm{BPH}$ nymphs per hill until $90 \%$ of TN-1 starts wilting. Genotypes which were most preferred by BPH were declared as susceptible and do not possess antixenosis mechanism and vice versa, after comparing with the load of BPH nymphs on susceptible and resistant checks following the method of Heinrichs et al. (1985). Each genotype was replicated three times and the whole experiment was repeated twice to attain more accurate results and appropriate conclusion.

\section{Tolerance}

Experiments on testing the tolerance mechanism were also carried out by measuring parameters such as functional plant loss index (FPLI) and tolerance index (TI) by following the methodology described by Panda and Heinrichs (1983) and Hu et al. (2015) with a few modifications.

About 20 pre-germinated seedlings of each variety were sown in a $10 \mathrm{~cm}$-diameter clay pot placed in a $68 \mathrm{~cm} \times 42 \mathrm{~cm} \times 16 \mathrm{~cm}$ plastic seed box. About $2 \mathrm{~cm}$ of water was maintained in the seed-box until the experiment was finished. Seven days after sowing, seedlings were thinned to 6 plants per pot. At the third-leaf stage, 1st instar nymphs (10 numbers) were placed on each plant. The potted plants were then covered with cylindrical Mylar cages $(13 \mathrm{~cm} \times 50 \mathrm{~cm})$. Three control plants without insects were maintained for each line. When the control TN1 plants started to wilt, the experiment was stopped and the BPH nymphs were collected from each line, ovendried for $48 \mathrm{~h}$ and weighed. Infested and non-infested plants were removed from the pots along with the roots, washed thoroughly, air dried for $3 \mathrm{~h}$, then dried in an oven at $65^{\circ} \mathrm{C}$ for $60 \mathrm{~h}$ and weighed. The level of tolerance was assessed using the parameters FPLI and TIs. A scatter plot was set up with the $x$-axis representing the weight of insects and the $y$-axis representing the FPLI. The transept of average $\mathrm{BPH}$ weight and the regression line divided the scatter plot into four sectors representing high antibiosis and low tolerance, high tolerance and low antibiosis, high antibiosis and high tolerance, and low antibiosis and low tolerance (susceptibility), as described by Panda and Heinrichs (1983). Six replicates of each cultivar and four replications of whole experiment were carried out. The FPLI and TI were estimated by following formula,

$$
\begin{array}{r}
\text { FPLI }=100-\left(\frac{\text { dry weight of infested plant }}{\text { dry weight of non-infested plant }}\right) x \\
\left(1-\frac{\text { damage }}{9}\right) \times 100 \\
T I=\frac{B P H \text { weight on test line }}{\text { BPH weight on susceptible control }(T N-1)}
\end{array}
$$

Assessment of broad-spectrum antibiosis of CR2711-76 against different populations of BPH

Antibiosis experiments were also conducted to assess the broad spectrum resistance of resistant donor CR2711-76 
using different populations of BPH, Laguna, Isabela, Bicol and Nueva Ecijia of the Philippines; and biotype 4 of India with three replications. The varieties which show resistance reaction to all the different $\mathrm{BPH}$ populations of the Philippines and the biotype 4 of India were declared as genotype/s with broad-sense resistance.

\section{Inheritance of antibiosis on feeding rate}

The inheritance pattern of antibiosis on feeding rate between Jaya and CR2711-76 was studied, The $\mathrm{F}_{1} \mathrm{~s}$ generated from the cross of Jaya and CR2711-76, parental lines along with the checks were bioassayed for antibiosis on feeding rate for Laguna and Nueva Ecijia BPH colonies in two replications.

\section{Fine mapping of the $B P H 31$ gene}

Genomic DNA was extracted by the modified CTAB method as described by Kim et al. (2011). Simple sequence repeat (SSR) and sequence tagged site (STS) markers were used to identify the gene and its introgression. PCR reactions were carried out with standard PCR buffers and conditions. The thermal profile followed was 4 min at $94{ }^{\circ} \mathrm{C}$, followed by 35 cycles of $1 \mathrm{~min}$ at $94{ }^{\circ} \mathrm{C}$, $30 \mathrm{~s}$ at $55^{\circ} \mathrm{C}$, and $1 \mathrm{~min}$ at $72{ }^{\circ} \mathrm{C}$, with a final extension of $10 \mathrm{~min}$ at $72{ }^{\circ} \mathrm{C}$. Amplification products were separated by electrophoresis in 3.5\% agarose gel or $8.0 \%$ nondenaturing PAGE. In total, 812 SSR and STS primer sets were tested for the polymorphism on the parental lines, Jaya and CR2711-76. Among them, 107 markers showed polymorphic PCR bands between the parents and they were potentially used for characterizing the alleles existing among the $151 \mathrm{~F}_{2}$ plants. MAPMAKER/EXP 3.0 (Lincoln et al. 1992) was used to construct the linkage map from the 107 markers spanning the 12 rice chromosomes. The Kosambi mapping function (Kosambi 1944) was used to convert recombination fractions to map distances in centiMorgans (cM).

The precisely estimated phenotypic data and welldistributed marker genotype data were used for locating genomic regions conferring BPH resistance. QTL IciMapping software ver. 4.0 (Meng et al. 2015) with 1000 permutations at 0.01 significance LOD threshold and its results were validated with WinQTL cartographer ver. 2.5 (Wang 2012) considering the same threshold parameters.

Based on the whole genome sequence of reference genome Nipponbare, TIGR prediction method (http://rice.plantbiology.msu.edu/), available information from the 3000 Rice Genome Project (3 K RGP), and OryzaSNP (http://snp-seek.irri.org/) database, 27 putative InDel markers were designed to narrow down the BPH31 locus and were surveyed for polymorphism between Jaya and CR2711-76. The markers detecting polymorphism between Jaya and CR2711-76 were further tested on the $F_{2}$ mapping population and these markers segregated for marker alleles in the $\mathrm{F}_{2}$ progenies. Furthermore, QTL analysis was performed again by retaining the same threshold parameters to identify the markers closely linked to BPH31. All candidate genes within the identified region were analyzed based on the information available in NCBI (https:// www.ncbi.nlm.nih.gov/unigene), TIGR release 7.1 (http:// rice.plantbiology.msu.edu/), RiceXPro (Sato et al. 2013; http://ricexpro.dna.affrc.go.jp/) and Rice oligonucleotide array data base (http://www.ricearray.org/expression/ meta_analysis.shtml).

\section{Validation of $В P H 31$ flanking markers for MAS}

To investigate the accuracy of the identified marker, a $\mathrm{BC}_{2} \mathrm{~F}_{2}$ population consisting of 268 individuals derived from a heterozygous line of $\mathrm{BC}_{2} \mathrm{~F}_{1}, \mathrm{BC}_{1} \mathrm{~F}_{1}-61-\mathrm{BC}_{2} \mathrm{~F}_{1}-19$ 13-(33-13)- $\mathrm{BC}_{2} \mathrm{~F}_{2}-11-20$, and a homozygous recessive line, $\mathrm{BC}_{1} \mathrm{~F}_{1}-35-\mathrm{BC}_{2} \mathrm{~F}_{1}-8-12(17-14)-\mathrm{BC}_{2} \mathrm{~F}_{2}-271-280$, were screened for $\mathrm{BPH}$ resistance using the modified standard seed box method (Jena et al. 2006). For this experiment, $149 \mathrm{BC}_{2} \mathrm{~F}_{2}$ seeds obtained from a heterozygous line and $119 \mathrm{BC}_{2} \mathrm{~F}_{2}$ seeds from a homozygous recessive line were sown in blue trays. The segregation for $\mathrm{BPH}$ resistance was studied in the populations by directly assaying the phenotype of the $\mathrm{BC}_{2} \mathrm{~F}_{2}$ individuals. The genotype and phenotype of all these $\mathrm{BC}_{2} \mathrm{~F}_{2}$ individuals were compared and percent co-segregation for markers within the preliminary mapped locus was computed. The markers with high co-segregation were identified and recommended for marker assisted introgression.

\section{Background genotyping and construction of a graphical genotype map}

To determine the genetic background recovery of the $\mathrm{BC}_{2} \mathrm{~F}_{1}$ progenies, a high-density SNP marker genotyping system, Infinium $6 \mathrm{~K}$ SNP chip assay was employed. The Infinium platform detects SNP alleles by adding a fluorescence-labeled allele-specific nucleotide (allele-specific hybridization) via single-base extension and subsequent detection of the fluorescence color. Generated HapMap format SNPs were sorted and filtered out for no calls and monomorphism between the parents before they were used for the computation of percent recovery of the recurrent parent genome. Finally, the graphical genotype map was drawn based on the filtered SNP genotype data using the web tool PhenoGram (http:// visualization.ritchielab.psu.edu/phenograms/plot).

\section{Statistical analysis}

A randomized complete block design (RCBD) was employed to analyze the data obtained from the bioassay of parental lines to test the significance of the experiments. Fisher's least significant difference (LSD) test and Duncan's multiple range test (DMRT) at $\alpha=0.05$ and $/$ or 0.01 significance were used to 
compare the means of the test entries and to infer the significant difference between the cultivars under study. Maximum likelihood (multiple regression analysis) was employed for composite interval mapping for preliminary and fine mapping of $B P H 31$. Chisquare goodness-of-fit was employed to fit the segregation pattern of $B P H 31$ based on the genotypic and phenotypic ratios, to study the genetics of resistance and also inheritance of the antibiosis mechanism. The Chi-square test for goodness-of-fit was performed manually using MS-Excel. Simple linear regression and pooled regression analysis were calculated in the tolerance experiment to classify the different mechanisms of resistance into different sectors (Panda and Heinrichs 1983).

\section{Statement}

Statement I confirm that we have followed the guide lines of the government of The Philippines and the policies of IRRI for growing rice plants and carrying out research study.

\section{Addtional files}

Additional file 1: Figure S1. Graphical representation of area of honeydew secretion of (a) first experiment, (b) repeated experiment for Isabela BPH colony, (c) for Bicol BPH colony, and (d) for Nueva Ecijia BPH colony; among the test genotypes including parental lines, Jaya and CR2711-76; $P_{1}, P_{2}, 13 \mathrm{t}, \mathrm{RH}$, and $F_{1}$ are Jaya, CR2711-76, BPH13 donor line, Rathu Heenati, and $F_{1}$ is the hybrid of Jaya $\times$ CR2711-76, respectively; $\mathrm{RH}$ and $\mathrm{TN}-1$ are resistant and susceptible checks. (PPTX $178 \mathrm{~kb}$ )

Additional file 2: Figure S2. Photograph depecting the area of honeydew secreated when Lagun colony of BPH fed on TN-1, Rathu Heenati, CR2711-76 and Jaya testlines. (PPTX $287 \mathrm{~kb}$ )

Additional file 3: Figure S3. Rice molecular linkage map obtained from 107 SSR and STS markers of $151 \mathrm{~F}_{2: 3}$ mapping population of the cross combination Jaya $\times$ CR2711-76. Chromosome numbers are presented on the top of each linkage group, marker names are presented on the right side of each linkage group, and their intervals in $\mathrm{CM}$ are presented on the left side of the linkage group. This linkage group was generated by QTL IciMapping software considering the marker position and order retrieved from MAPMAKER ver. 2.0. (PPTX $160 \mathrm{~kb}$ )

Additional file 4: Figure S4. The schematic diagram of primary mapped $\mathrm{BPH}$ resistance locus BPH31 on chromosome 3 flanked by RM251 and RM2334 with 48.40 LOD and $80.71 \%$ phenotypic variance explained derived from $151 \mathrm{~F}_{2: 3}$ mapping population in the whole-genome view. This result was retrieved from the linkage analysis of (a) QTL IciMapping ver. 4.0 (Meng et al. 2015) and (b) WinQTL cartographer ver. 2.5 (Wang 2012) software package. (PPTX $658 \mathrm{~kb}$ )

Additional file 5: Figure S5. (a) Raw signal intensity bar graph (in silico gene expression analysis as available in public domain, http://rice xpro.dna.affrc.go.jp/GGEP/graph-view.php?featurenum=29277) showing the expression intensity of LOC_Os03g46550 gene. (b) Preferential gene expression at different developmental stages of the rice plant. (c) Tissuespecific differential expression of LOC_Os03g46550 (based on information available at http://www.ricearray.org/expression/meta_analysis.shtml). (PPTX $706 \mathrm{~kb}$ )

Additional file 6: Figure S6. Photograph showing the bioassay result of negative and positive $\mathrm{BPH} 31 \mathrm{BC}_{2} \mathrm{~F}_{2} \mathrm{~S}$ of marker validation experiment at maximum lethal stage (ninth day after infestation) for the Laguna BPH population. (PPTX $296 \mathrm{~kb}$ )

Additional file 7: Figure S7. Schematic diagram showing material generation for the identification and introgression of BPH31. (PPTX $71 \mathrm{~kb}$ )

Additional file 8: Figure S8. Photograph showing the typical bioassay conducted using CR2711-76, Jaya, Rathu Heenati and TN-1 along with other test lines. (PPTX 542 KB)

Additional file 9: Figure S9. Graphical representation of 7 years $\mathrm{BPH}$ (biotype 4) bioassay result of parental lines and checks. (PPTX 171 KB)

Additional file 10: Figure S10. Graphical representation of comparative resistance reaction of $\mathrm{BPH} 31$ with already identified genes against Laguna BPH colony. (PPTX $128 \mathrm{~kb}$ )

Additional file 11: Table S1. List of newly designed InDel markers for fine mapping of BPH31. (PPTX $77 \mathrm{~kb}$ )

Additional file 12: Table S2. List of candidate genes identified within the fine-mapped region $(475 \mathrm{~kb}$ ) along with their putative function. (PPTX 86 kb)

Additional file 10: Table S3. Seven years BPH (biotype 4) bioassay result of parental lines and checks. Phenotypic values are the average seedling survival rates. (PPTX $55 \mathrm{~kb}$ )

\section{Abbreviations}

$\mathrm{BPH}$ : Brown planthopper; CTAB: Cetyl trimethylammonium bromide; DMRT: Duncan's multiple range test; FPLI: Functional plant loss index; LOD: Logarithms of odds; LSD: Least significant difference; MAS: Marker assisted selection; NCBI: National centre for biotechnology information; NIL: Near isogenic line; PCR: Polymerase chain reaction; QTL: Qunatitative trait locus; RCBD: Randomized complete block design; SES: Standard evealuation system; SNP: Single nucleotide polymorphism; SSR: Simple sequence repeat; STS: Sequence tagged site; TI: Tolerance index; TN-1: Tai-chung Native-1; ZARS: Zonal agricultural research station

\section{Acknowledgments}

We would like to thank Mr. Onkaranna and other technicians in the Hybrid Rice Division, ZARS, VC Farm, Mandya, Karnataka, India, and Mr. Dante, Ms. Apul, and Ms. Sherry-Lou Hechanova of the NGR group at IRRI, Philippines, for providing excellent assistance during the experiment. We extend our thanks to the Department of Agriculture, Government of Karnataka; NRRI, ICAR, India; Dr. Vandana Tyagi, National Bureau of Plant Genetic Resources, Ministry of Agriculture and Farmers' Welfare, Government of India; and INGER, IRRI for helping in the transfer of seed materials by fulfilling all the necessary requirements of intellectual property rights during the exchange of materials. We thank Bill Hardy of IRRI Communication for editing of the manuscript.

\section{Funding}

We are grateful to the Global Rice Science Scholarship Program (GRiSSP Grant No. A-2012-180) of IRRI for the financial support to GDP for PhD research.

\section{Availability of data and materials}

All relevant data are provided as Tables within the paper and in the Supporting Information files.

\section{Authors' contributions}

KKJ (k.jena@irri.org) and SN conceived the idea and wrote the manuscript. PGD (g.d.prahalada@irri.org) conducted research, analyzed data, designed InDel markers, and drafted the manuscript. SH, LHC, and RC participated in setting up the initial experiments. RG and SRK designed candidate genespecific markers using bioinformatics tools. SDK maintained pure culture of $\mathrm{BPH}$ (biotype 4) colonies and conducted BPH bioassays during 2009 and 2010. TM shared the seeds of the resistant donor and reviewed the manuscript. All authors read and approved the final manuscript.

\section{Ethics approval and consent to participate}

This study complied with the ethical standards of India and the Philippines, where this research work was carried out. 


\section{Competing interests}

The authors declare that they have no competing interests.

\section{Publisher's Note}

Springer Nature remains neutral with regard to jurisdictional claims in published maps and institutional affiliations.

\section{Author details}

'Plant Breeding Division, International Rice Research Institute, DAPO Box 7777, Metro Manila, Philippines. ${ }^{2}$ Zonal Agricultural Research Station, VC Farm, Mandya, Karnataka, India. ${ }^{3}$ College of Agriculture, Mandya, Karnataka, India. ${ }^{4}$ University of Agricultural Sciences, GKVK, Bangalore, Karnataka, India. ${ }^{5}$ Indian Council of Agricultural Research, New Delhi, India.

Received: 22 June 2017 Accepted: 11 August 2017

Published online: 31 August 2017

\section{References}

Alam SN, Cohen MB (1998) Detection and analysis of QTLs for resistance to the brown planthopper, Nilaparvata lugens, in a doubled haploid rice population. Theor Appl Genet 97:1370-1379

Brar DS, Virk PS, Jena KK, Khush GS (2010) Breeding for resistance to planthoppers in rice. Planthopper: newthreats to the sustainability of intensive rice production systems in Asia. International Rice Research Institute, Los Baños, pp 401-427

Cabauatan PQ, Cabunagan RC, Choi IR (2009) Rice viruses transmitted by the brown planthopper Nilaparvata lugens Stål. Planthoppers: new threats to the sustainability of intensive rice production systems in Asia (ed. by KL Heong \& B Hardy). International Rice Research Institute, Los Baños, pp 357-368

Cha YS, Ji H, Yun DW, Ahn BO, Lee MC, Suh SC, Lee CS, Ahn EK, Jeon YH, Jin ID, Sohn JK, Koh HJ, Eun MY (2008) Fine mapping of the rice Bph1 gene, which confers resistance to the brown planthopper (Nilaparvata lugens Stal) and development of STS markers for marker-assisted selection. Mol Cell 26:146-151

Chen JW, Wang L, Pang XF, Pan QH (2006) Genetic analysis and fine mapping of a rice brown planthopper (Nilaparvata lugens Stal) resistance gene bph19(t). Mol Gen Genomics 275:321-329

Cheng XY, Zhu LL, He GC (2013) Towards understanding of molecular interactions between rice and the brown planthopper. Mol Plant 6:621-634

Cohen MB, Alam SN, Medina EB, Bernal CC (1997) Brown planthopper (Nilaparvata lugens) and resistance in rice cultivar IR64: mechanism and role in successful N. lugens management in central Luzon, Philippines. Entomol Exp Appl 85:221-229

Deen R, Ramesh K, Gautam SK, Rao YK, Lakshmi VJ, Viraktamath BC, Brar DS, Ram $\mathrm{T}$ (2010) Identification of new gene for BPH resistance introgressed from 0 . rufipogon. Rice Genet Newsl 25:70-72

Deen R, Ramesh K, Padmavathi G, Viraktamath BC, Ram T (2017) Mapping of brown planthopper [Nilaparvata lugens (Sta')]. Euphytica 213:35 doi: 10.1007/ s10681-016-1786-Z

Du B, Zhang W, Liu B, Hu J, Wei Z, Shi Z, He R, Zhu L, Chen R, Han B, He G (2009) Identification and characterization of Bph14, a gene conferring resistance to brown planthopper in rice. Proc Natl Acad Sci U S A 106:22163-22168

He J, Liu YQ, Liu YL, Jiang L, Wu H, Kang HY, Liu SJ, Chen LM, Liu X, Cheng XN, Wan JM (2013) High-resolution mapping of brown planthopper (BPH) resistance gene Bph27(t) in rice (Oryza sativa L.) Mol Breed 31:549-557

Heinrichs EA, Medrano FG, Rapusas HR (1985) Genetic evaluation for insect resistance in rice. International Rice Research Institute, Manila, p 356

Horgan FG, Ramal AF, Bentur JS, Kumar R, Bhanu KV, Sarao PS, Iswanto ES, Chien HV, Phyu MH, Bernal CC, Almazan MLP, Alam MZ, Lu Z, Huang S (2015) Virulence of brown planthopper (Nilaparvata lugens) populations from south and South East Asia against resistant rice varieties. Crop Prot 78:222-231

Hu J, Li X, Wu C, Yang C, Hua H, Gao G, Xiao J, He Y (2012) Pyramiding and evaluation of the brown planthopper resistance genes Bph14 and Bph15 in hybrid rice. Mol Breed 1:61-69

Hu J, Xiao C, Cheng M, Gao G, Zhang Q, He Y (2015) Fine mapping and pyramiding of brown planthopper resistance genes QBph3 and QBph4 in an introgression line from wild rice $O$. officinalis. Mol Breed 35:3

Huang D, Qiu Y, Zhang Y, Huang F, Meng J, Wei S, Li R, Chen B (2013) Fine mapping and characterization of $\mathrm{BPH} 27$, a brown planthopper resistance gene from wild rice (Oryza rufipogon Griff.) Theor Appl Genet 126:219-229

IRRI (1996) Standard evaluation system for rice. IRRI, Philippines
Jena KK, Jeung JU, Lee JH, Choi HC, Brar DS (2006) High resolution mapping of a new brown planthopper (BPH) resistance gene, Bph18(t) and marker-assisted selection for BPH resistance in rice (Oryza sativa L.) Theor Appl Genet 112:288-297

Ji H, Kim SR, Kim YH, Suh JP, Park HM, Sreenivasulu N, Misra G, Kim SM, Hechanova SL, Kim H, Lee GS, Yoon UH, Kim TH, Lim H, Suh SC, Yang J, An J, Jena KK (2016) Map-based cloning and characterization of the Bph18 gene from wild rice conferring resistance to brown planthopper (BPH) insect pest. Sci Rep 6:34376

Khush GS (1979) Genetics of resistance and breeding for resistance to the brown planthopper. In: International Rice Research Institute (ed) Brown planthopper: threat to rice production in Asia. IRRI, Los Baños, pp 321-332

Khush GS, Karim AN, Angeles ER (1985) Genetics of resistance of rice cultivar ARC 10550 to Bangladesh brown planthopper biotype. J Genet 64:121-125

Kim SR, Jeon JS, An G (2011) Development of an efficient inverse PCR method for isolating gene tags from T-DNA insertional mutants in rice. Methods Mol Biol 678:139-146

Kosambi DD (1944) The estimation of map distance from recombination values. Ann Eugenics 12:172-175

Lincoln S, Daly M, Lander E (1992) Constructing genetic maps with Mapmaker/ exp 3.0. In: Whitehead institute technical report, Cambridge, MA, USA

Liu YQ, Wu H, Chen H, Liu YL, He J, Kang HY, Sun ZG, Pan G, Wang Q, Hu JL, Zhou F, Zhou KN, Zheng XM, Ren YL, Chen LM, Wang YH, Zhao ZG, Lin QB, Wu FQ, Zhang X, Guo XP, Cheng XN, Jiang L, Wu CY, Wang HY, Wan JM (2015) A gene cluster encoding lectin receptor kinases confers broadspectrum and durable insect resistance in rice. Nat Biotechnol 33:301-305

Lv WT, Du B, Shangguan XX, Zhao Y, Pan Y, Zhu L, He Y, He G (2014) BAC and RNA sequencing reveal the brown planthopper resistance gene BPH15 in a recombination cold spot that mediates a unique defense mechanism. BMC Genomics 15:674-589

Mackenzie DR (1980) The problem of variable pests. In: Breeding plants resistant to insects. John Wiley, New York, pp 183-213

Meng L, Li H, Zhang L, Wang J (2015) QTL IciMapping: integrated software for genetic linkage map construction and quantitative trait locus mapping in biparental populations. Crop J 3:269-283

Myint KKM, Fujita D, Matsumura M, Sonoda T, Yoshimura A, Yasui H (2012) Mapping and pyramiding of two major genes for resistance to the brown planthopper (Nilaparvata lugens [Stal]) in the rice cultivar ADR52. Theor Appl Genet 124:495-504

Normile D (2008) Reinventing rice to feed the world. Science 321:330-333

Panda N, Heinrichs EA (1983) Levels of tolerance and antibiosis in rice varieties having moderate resistance to the brown planthopper, Nilaparvata lugens (Stal; Hemiptera: Delphacidae). Environ Entomol 12:1204-1214

Pathak PK, Heinrichs EA (1982) Bromocresol green indicator for measuring feeding activity of Nilaparvata Lugens on rice varieties. Philippine Entomologist 5:197-198

Pathak MD, Khush GS (1979) Studies of varietal resistance in Rice to the Brown planthopper at the international rice research institute. In: IRRI (ed) brown planthopper: threat to rice production in Asia. IRRI, Los Banõs, pp 285-301

Qiu Y, Guo J, Jing S, Zhu L, He G (2012) Development and characterization of japonica rice lines carrying the brown planthopper-resistance genes BPH12 and BPH6. Theor Appl Genet 124:485-494

Ramkumar G, Prahalada GD, Hechanova SL, Kim SR, Jena KK (2016) Exploring genetic diversity of rice cultivars for the presence of brown planthopper (BPH) resistance genes and development of SNP marker for Bph18. Plant Breed 10.1111/pbr.12365

Ren J, Gao F, Wu X, Zeng L, LV J, Su X, Luo H, Ren G (2016) BPH32, a novel gene encoding an unknown SCR domain-containing protein, confers resistance against the brown planthopper in rice. Sci Rep 6:37645 doi: 10.1038/srep37645.8

Sato Y, Takehisa H, Kamatsuki K, Minami H, Namiki N, Ikawa H, Ohyanagi H, Sugimoto K, Antonio B, Nagamura Y (2013) RiceXPro version 3.0: expanding the informatics resource for rice transcriptome. Nucleic Acids Res 41:1206-1213

Saxena R, Barrion A (1985) Biotypes of the brown planthopper Nilaparvata lugens (Stål) and strategies in deployment of host plant resistance. Insect Science and Its Application 6(3):271-289 doi:10.1017/S1742758400004549

Sogawa K, Liu GJ, Shen JH (2003) A review on the hyper-susceptibility of Chinese hybrid rice to insect pests. Chin J Rice Sci 17:23-30

Sun LH. Su CC, Wang CM, Zai HQ, Wan JM (2005) Mapping of a major resistance gene to brown planthopper in the rice cultivar Rathu Heenati. Breed Sci 55: 391-396.

Sun LH, Wang CM, Su CC, Liu YQ, Zhai HQ, Wan J (2006) Mapping and markerassisted selection of a brown planthopper resistance gene bph2 in rice (Oryza sativa L.) Acta Genet Sin 33:717-723 
Tamura Y, Hattori M, Yoshioka H, Yoshioka M, Takahashi A, Wu J, Sentoku N, Yasui H (2014) Map-based cloning and characterization of a brown planthopper resistance gene BPH26 from Oryza Sativa L. Ssp. Indica cultivar ADR52. Sci Rep 4:5872

Tanaka K, Endo S, Kazano H (2000) Toxicity of insecticides to predators of rice planthoppers: spiders, the mired bug and the dryinid wasp. Appl Entomol Zool 35:177-187

Wang S, Basten CJ, Zeng ZB (2012) Windows QTL cartographer 2.5. Department of Statistics, North Carolina State University, Raleigh

Wang Y, Cao L, Zhang Y, Cao C, Liu F, Huang F, Qiu Y, Li R, Lou X (2015) Map-based cloning and characterization of $\mathrm{BPH} 29$, a B3 domain-containing recessive gene conferring brown planthopper resistance in rice. J Exp Bot 106:326-331

Wu H, Liu Y, He J, Liu Y, Jiang L, Liu L, Wang C, Cheng X, Wan J (2014) Fine mapping of brown planthopper (Nilaparvata lugens Stål) resistance gene Bph28(t) in rice (Oryza sativa L.) Mol Breed 33:909-918

Zhao Y, Huang J, Wang Z, Jing S, Wang Y, Ouyang Y, Cai B, Xin XF, Liu X, Zhang C, Pan Y, Ma R, Li Q, Jiang W, Zeng Y, Shangguan X, Wang H, Du B, Zhu L, Xu X, Feng YQ, He SY, Chen R, Zhang Q, He G (2016) Allelic diversity in an NLR gene BPH9 enables rice to combat planthopper variation. PNAS 113(45): $12850-12855$

\section{Submit your manuscript to a SpringerOpen ${ }^{\circ}$ journal and benefit from:}

- Convenient online submission

- Rigorous peer review

- Open access: articles freely available online

- High visibility within the field

- Retaining the copyright to your article

Submit your next manuscript at $\gg$ springeropen.com 